EMBRYARIDDLE
Aeronautical University

SCHOLARLY COMMONS

\section{International Journal of Aviation,} Aeronautics, and Aerospace

\title{
Structural and technological complex of methods for processing satellite images
}

\author{
Rasul Zairovich Shamsiev \\ Tashkent State Transport University, rasulshamsiev@rambler.ru \\ Zair Ziyaevich Shamsiev \\ Tashkent state transport university, shamzz@rambler.ru
}

Follow this and additional works at: https://commons.erau.edu/ijaaa

Part of the University Extension Commons

\section{Scholarly Commons Citation}

Shamsiev, R. Z., \& Shamsiev, Z. Z. (2021). Structural and technological complex of methods for processing satellite images. International Journal of Aviation, Aeronautics, and Aerospace, 8(2). https://doi.org/10.15394/ijaaa.2021.1583

This Article is brought to you for free and open access by the Journals at Scholarly Commons. It has been accepted for inclusion in International Journal of Aviation, Aeronautics, and Aerospace by an authorized administrator of Scholarly Commons. For more information, please contact commons@erau.edu. 
Currently, satellite images are used to solve a wide range of problems. A variety of remote sensing tasks give rise to a very large number of specific methodological methods for solving them. Decoding satellite images involves hundreds of automated methods. These methods are included in the modules of many well-known software tools for processing satellite images. To solve specific problems of identifying individual natural or man-made objects, there is a problem of choosing a method and means of data processing. The choice of methods depends on the scope of their application, different data are selected, for example, high-and low-resolution images, corresponding cartographic or other types of data. To solve this problem, a structural and technological complex processing method is proposed. Since the initial processing of images is followed by thematic processing by industry, let's consider this method using the example of recognition of geological objects.

The research methodology for solving the tasks set includes the following types of work:

1. Selection and analysis of satellite images;

2. Selection and analysis of satellite images processing software products;

3. Selection and analysis of satellite images processing methods;

4. Experimental part.

\section{Satellite Images Selection and Analysis}

The main characteristics of remote sensing materials are the scale or spatial resolution of the images, i.e., the detail of the image, their type (black-and-white, color, multi-zone, in the visible, infrared, or radio bands of the electromagnetic spectrum), the season and time of shooting. The choice of images with certain characteristics depends crucially on the purpose of the research and the properties of the territory to be studied.

It is important to keep in mind at least three circumstances. The first is the minimum size of the objects that are supposed to be decrypted or displayed on the map in accordance with the scale at which it will be compiled. In most cases, it is necessary to focus not only on the size of the objects that are the subject of observations, but also on smaller objects, since they can provide additional information during recognition. The second is the severity and clarity of the borders of the objects to be decoded: the clearer the borders of the objects, the more detailed the image can be used.

At the same time, it makes no sense to use very detailed images to decipher objects with poorly defined borders in the form of a transition band. It is known that such boundaries become clearer as the scale decreases. For example, it does not make sense to decipher the boundary of snow cover or surface moraines on a glacier from ultra-high-resolution images (less than $2 \mathrm{~m}$ ), since they do not have a clear boundary. 
The third is the interval of repeated observations (Shamsiev, 2013). In general, higher-resolution images are needed to detect seasonal changes than to detect long-term changes. When analyzing the information features of satellite images, consider the classification table for the technology of obtaining the image, visibility, and spatial resolution (Table 1).

\section{Table 1}

\section{Classifications}

\begin{tabular}{|c|c|c|}
\hline \multirow[t]{2}{*}{$\begin{array}{l}\text { Technology for } \\
\text { taking a snapshot }\end{array}$} & $\begin{array}{l}\text { Visible infrared range. Passive, detect } \\
\text { natural radiation }\end{array}$ & $\begin{array}{l}\text { Photographic Scanner OM } \\
\text { Scanner OE }\end{array}$ \\
\hline & $\begin{array}{l}\text { Radio range, active (registers artificial } \\
\text { radiation) }\end{array}$ & Radar stations \\
\hline \multirow{4}{*}{$\begin{array}{l}\text { Classification of } \\
\text { images by visibility }\end{array}$} & Global & $10,000 \mathrm{~km}$ \\
\hline & Large-regional & $500-3000 \mathrm{~km}$ \\
\hline & Regional & $50-500 \mathrm{~km}$ \\
\hline & Local & $10-50 \mathrm{~km}$ \\
\hline \multirow{7}{*}{$\begin{array}{l}\text { Classification of } \\
\text { images by spatial } \\
\text { resolution }\end{array}$} & Low & kilometers \\
\hline & Average & hundreds of meters \\
\hline & High: & tens of meters \\
\hline & Relatively high & $30-100 \mathrm{~m}$ \\
\hline & High & $10-30 \mathrm{~m}$ \\
\hline & Very high & meters \\
\hline & Ultra-high & fractions of a meter \\
\hline
\end{tabular}

Since the main purpose of the study is to recognize natural objects and compare them with cartographic data, the choice of satellite images also depends on the following reasons. The first is the spatial and temporal resolution, and the second depends on the tasks being solved. Based on the table of the ratio of time and spatial resolution, as well as the table of solved problems, the Landsat TM satellite image is optimal for studying the geological nature of the main decoded geological objects.

For accelerated spatial resolution processing, Landsat 7 is preferred. The size of a single Landsat $7 \mathrm{TM}$ stage covers an area of 180x170 km. The spatial resolution of Landsat 7 TM satellite images is up to 15 meters (Lehrer \& Bowen, 2003). This system conducts surveys in 8 spectral channels, including two thermal channels and one panchromatic channel, the set and combination of which by various methods, provides the identification of natural objects.

Processing of the multispectral satellite image of Landsat TM using an integrated approach in a combination of various automated methods to obtain the most complete representation of the structure of natural objects, which will later be used for more complex analysis of the recognition of objects in the satellite image. 
Object recognition requires a complex approach to processing satellite images. The approach should allow us to identify different spectral data separately, and then combine the obtained data into one final class structure and give them values for automated recognition using matching methods. In this regard, a general flowchart of the algorithm is proposed, which consists in multi-stage processing of the satellite image. The proposed algorithm is shown in Figure 1 and consists of the following steps:

\section{Figure 1}

Block Diagram of the Satellite Image Processing Algorithm

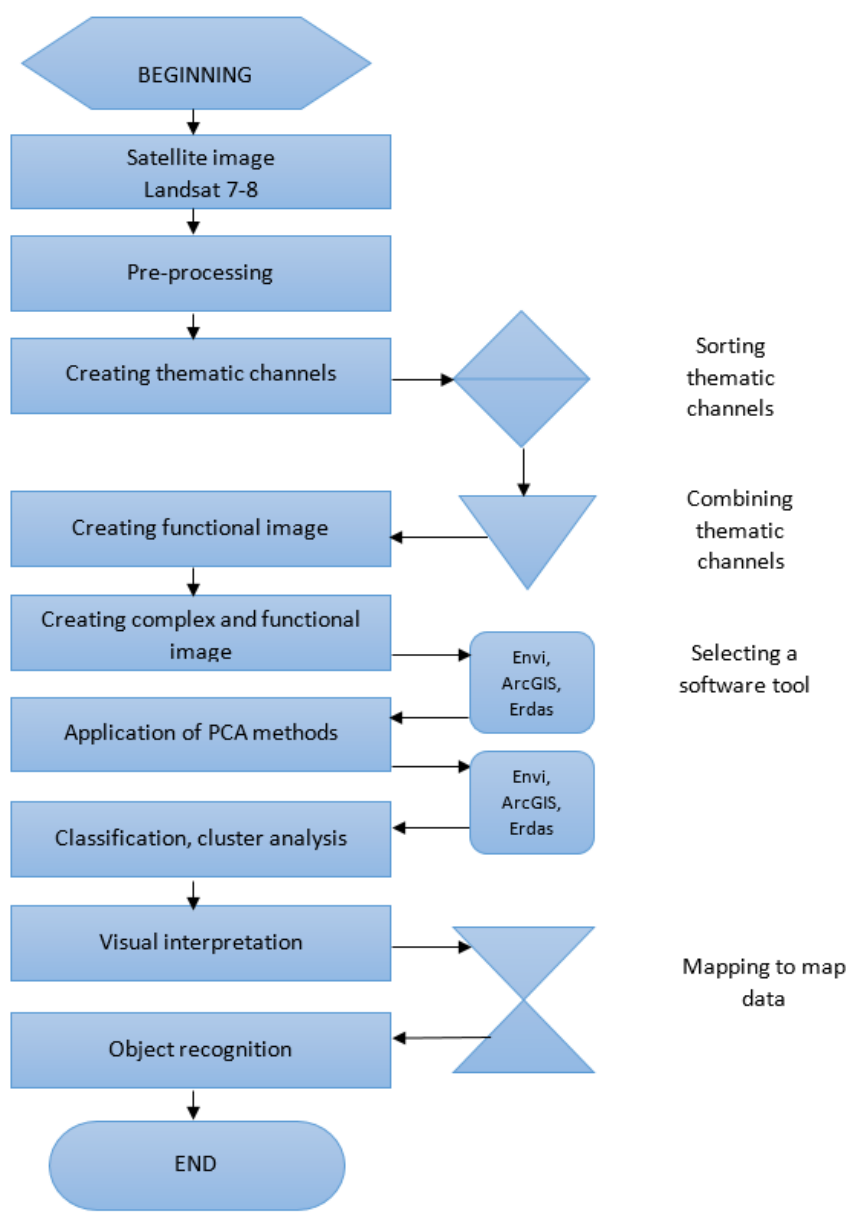

\section{Selection and Analysis of Satellite Images Processing Software Products}

Consider Table 2 of software products with an indication of their approximate number of modules (algorithms). 
Table 2

Number of Modules

Table №2.

\begin{tabular}{|l|c|c|c|c|c|c|}
\hline Software name & $\begin{array}{c}\text { ESRI } \\
\text { ArcMap } \\
\mathbf{9 . 3}\end{array}$ & $\begin{array}{c}\text { ERDAS } \\
\text { Imagine } \\
\mathbf{9 . 2}\end{array}$ & $\begin{array}{c}\text { ENVI } \\
\mathbf{4 . 7}\end{array}$ & $\begin{array}{c}\text { PCI } \\
\text { Geomatics } \\
\mathbf{2 0 1 2}\end{array}$ & $\begin{array}{c}\text { ArcView } \\
\text { GIS 3.2 }\end{array}$ & Total \\
\hline & 1 & 2 & 3 & 4 & 5 & - \\
\hline $\begin{array}{l}\text { Number of modules } \\
\text { (algorithms) }\end{array}$ & 600 & 190 & 460 & 440 & 70 & 1760 \\
\hline $\begin{array}{l}\text { Number of modules } \\
\text { as a percentage }\end{array}$ & $35 \%$ & $10 \%$ & $26 \%$ & $25 \%$ & $4 \%$ & $100 \%$ \\
\hline
\end{tabular}

As you can see in Table 2, the total number is 1760 algorithms from 5 programs. All algorithms are the connecting links of various operations for processing space and map materials in raster and vector formats (Shamsiev, 2016a). According to the total number of algorithms, ArcGIS 9.3 is more voluminous, but other programs with identical modules can give the most informative results and attract the user with a user-friendly interface and processing speed (Dony, 2001). For some types of processing, the information content prevails over the processing speed. Mathematical calculations of algorithms of one method can be supplemented and updated by different authors and are intended exclusively for other types of processing of a natural or man-made nature.

For an example of an experimental calculation based on the choice of a software product, we consider one of the modules called the PCA algorithm (main component analysis). This method is aimed at solving problems of identifying structures by compressing spectral space data.

After computational experiments using the Landsat 7 satellite image, processing results were obtained using ESRI, ERDAS Imagine, ENVI, and PCI Geomatics software using the PCA (Main Component Analysis) method (Figure 2). 
Figure 2

A Satellite Image That has Been Processed by the PCA Method in Various GIS Programs
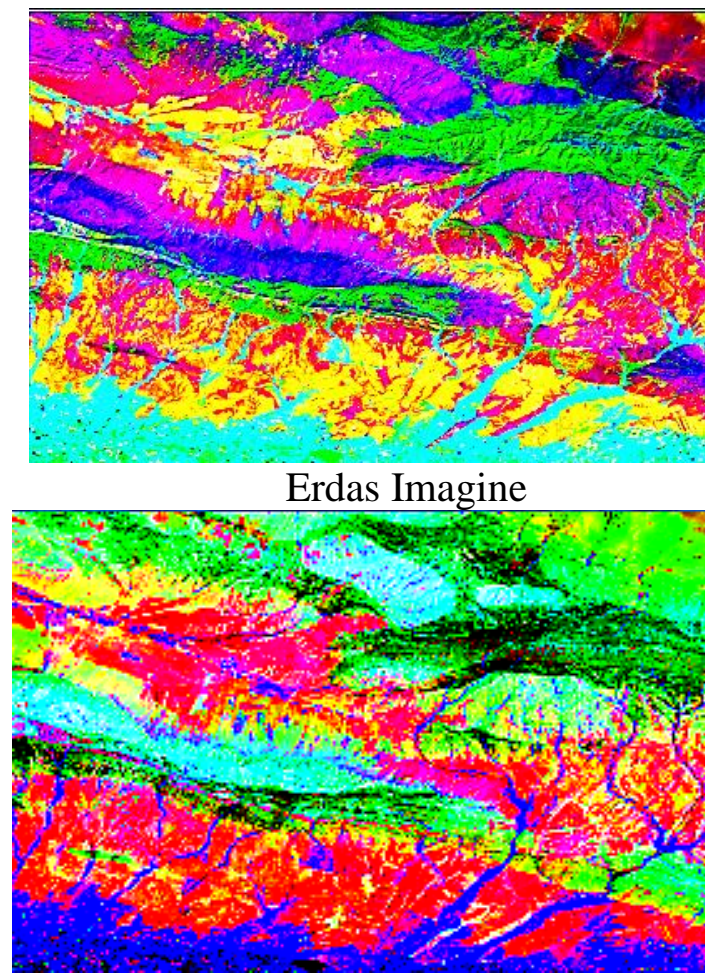

ENVI

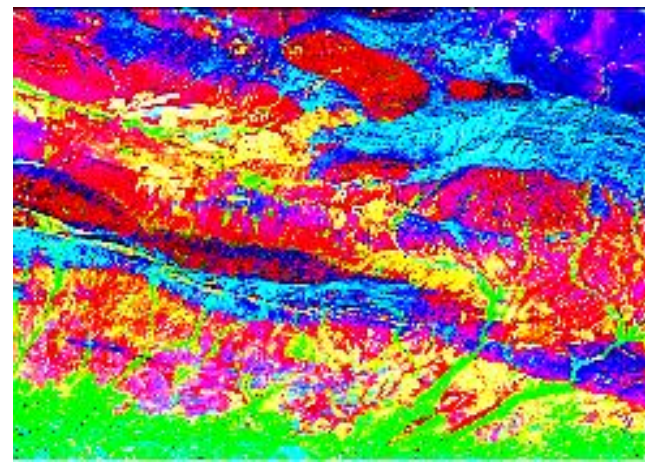

ArcGIS

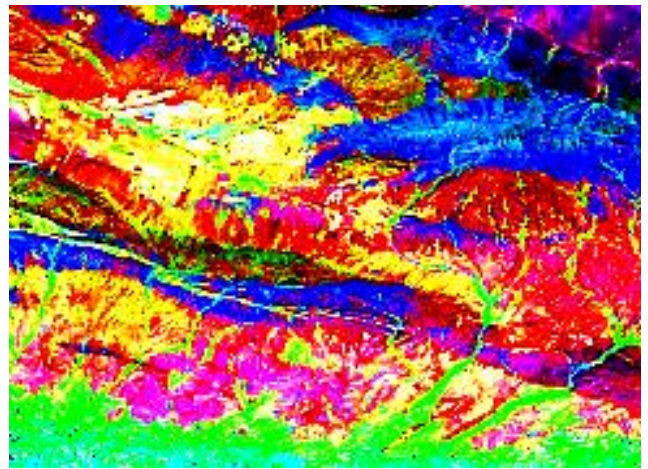

Geomatica

According to the experimental calculations, Table No. 3 was compiled, which included the entire list of the type of work, the characteristics of the image, the results on the time and properties of the identified objects. Of all the programs, the PCA module of the ENVI program is ahead of the modules of other programs in terms of information content, except for the processing speed and the output file size, these shortcomings can be eliminated by pre-selecting a combination of channels. 
Table 3

Type of Work

\begin{tabular}{|c|c|c|c|c|}
\hline List & $\begin{array}{c}\text { ArcGIS } \\
\text { (ArcMap 9.3) }\end{array}$ & $\begin{array}{c}\text { ERDAS } \\
\text { Imagine 9.2 }\end{array}$ & ENVI 4.7 & $\begin{array}{c}\text { PCI Geomatics } \\
2002 \\
\end{array}$ \\
\hline Types of models & PCA & PCA & PCA & PCA \\
\hline $\begin{array}{l}\text { The name of the } \\
\text { satellite image }\end{array}$ & Landsat 7 & Landsat 7 & Landsat 7 & Landsat 7 \\
\hline Type of satellite image & Spectral & Spectral & Spectral & Spectral \\
\hline $\begin{array}{l}\text { Number of spectral } \\
\text { channels }\end{array}$ & 7 & 7 & 7 & 7 \\
\hline $\begin{array}{l}\text { Resolution of the } \\
\text { satellite image }\end{array}$ & $\begin{array}{l}x(0,000297637 \\
59), \\
y(0,0002976375 \\
9)\end{array}$ & $\begin{array}{l}\mathrm{x}(0,0002976 \\
3759), \\
\mathrm{y}(0,0002976 \\
3759)\end{array}$ & $\begin{array}{l}\mathrm{x}(0,00029763 \\
759), \\
\mathrm{y}(0,00029763 \\
759)\end{array}$ & $\begin{array}{l}x(0,0002976375 \\
9), \\
y(0,0002976375 \\
9)\end{array}$ \\
\hline Scope of the study & $1: 200000$ & $1: 200000$ & $1: 200000$ & $1: 200000$ \\
\hline Research area & $\begin{array}{l}\text { Samarkand } \\
\text { region }\end{array}$ & $\begin{array}{l}\text { Samarkand } \\
\text { region }\end{array}$ & $\begin{array}{l}\text { Samarkand } \\
\text { region }\end{array}$ & $\begin{array}{l}\text { Samarkand } \\
\text { region }\end{array}$ \\
\hline $\begin{array}{l}\text { Processing speed with } \\
4 \text { GB of RAM }\end{array}$ & $\begin{array}{l}1 \mathrm{~min} 40 \mathrm{sec}+ \\
1 \mathrm{~min} \text { parameter } \\
\text { selection }\end{array}$ & $\begin{array}{l}2 \text { min } 15 \mathrm{sec} \\
+\quad 1 \mathrm{~min} \\
\text { parameter } \\
\text { selection }\end{array}$ & $\begin{array}{l}3 \text { min }+1 \min \\
\text { parameter } \\
\text { selection }\end{array}$ & $\begin{array}{l}1 \mathrm{~min}+1 \mathrm{~min} \\
\text { parameter } \\
\text { selection }\end{array}$ \\
\hline $\begin{array}{l}\text { Processing more than } \\
\text { three spectral channels }\end{array}$ & no & yes & yes & yes \\
\hline Ignoring null values & no & yes & yes & no \\
\hline $\begin{array}{l}\text { Combination of } \\
\text { spectral channels }\end{array}$ & no & yes & yes & yes \\
\hline Output file format & GRID Stack 7.x & Imagine & HDR & PIX \\
\hline Pixel Type & $\begin{array}{l}\text { unsigned } \\
\text { integer } 16\end{array}$ & $\begin{array}{l}\text { unsigned } \\
\text { integer } 8\end{array}$ & Float 32 & signed integer 8 \\
\hline Snapshot Type & continuous & continuous & continuous & continuous \\
\hline $\begin{array}{l}\text { Resolution of the } \\
\text { output satellite image }\end{array}$ & $\begin{array}{l}x(0,000257056 \\
21), \\
y(0,0002570562 \\
1)\end{array}$ & $\begin{array}{l}x(0,0002570 \\
5621), \\
y(0,0002570 \\
5621)\end{array}$ & $\begin{array}{l}x(0,00025705 \\
621), \\
y(0,00025705 \\
61) \\
\end{array}$ & $\begin{array}{l}\mathrm{x}(0,000257056 \\
21), \\
\mathrm{y}(0,000257056 \\
21)\end{array}$ \\
\hline $\begin{array}{l}\text { Number of spectral } \\
\text { channels of the output } \\
\text { file }\end{array}$ & 3 & 7 & 7 & 7 \\
\hline Source file size & $67,45 \mathrm{mb}$ & $67,45 \mathrm{mb}$ & $67,45 \mathrm{mb}$ & $67,45 \mathrm{mb}$ \\
\hline Output file size & $57,81 \mathrm{mb}$ & $75,28 \mathrm{mb}$ & $269,81 \mathrm{mb}$ & $67,49 \mathrm{mb}$ \\
\hline Integration & yes & yes & yes & no \\
\hline $\begin{array}{l}\text { of the Number of geol. } \\
\text { formats. objects }\end{array}$ & 35 & 60 & 70 & 52 \\
\hline $\begin{array}{l}\text { Number of landscape } \\
\text { objects (rivers, flora) }\end{array}$ & 1 (rivers) & $\begin{array}{l}2 \text { (rivers, } \\
\text { flora) }\end{array}$ & $\begin{array}{l}2 \\
\text { flora) }\end{array}$ & 2 (rivers, flora) \\
\hline $\begin{array}{l}\text { Number of man-made } \\
\text { objects }\end{array}$ & 1 (roads) & $\begin{array}{l}3 \text { (roads, } \\
\text { houses, } \\
\text { arable land) }\end{array}$ & $\begin{array}{l}4 \text { (roads, } \\
\text { houses, arable }\end{array}$ & $\begin{array}{l}2 \text { (roads, } \\
\text { houses, arable } \\
\text { land) }\end{array}$ \\
\hline
\end{tabular}




\begin{tabular}{|l|l|l|l|l|}
\hline & & & $\begin{array}{l}\text { land, power } \\
\text { lines) }\end{array}$ & \\
\hline $\begin{array}{l}\text { Sharpness of object } \\
\text { boundaries }\end{array}$ & low & average & high & average \\
\hline Blurring objects & high & average & low & medium, high \\
\hline $\begin{array}{l}\text { Color differences of } \\
\text { objects }\end{array}$ & low & average & high & average \\
\hline Visual informativeness & low & average & medium, high & average \\
\hline $\begin{array}{l}\text { Overall processing } \\
\text { quality }\end{array}$ & low & average & medium, high & low average \\
\hline
\end{tabular}

Selection and Analysis of Satellite Images Processing Methods

Based on the above review and analysis of software, we can conclude that a comprehensive system for the use of software products with the selection of the best algorithms through computational experiments, allows you to determine their capabilities for all processing parameters and distribute them by type of tasks in various areas of activity.

Let's consider the ratio algorithms on Landsat 7. This table (Table 4) describes the known methods (Kravtsov, 2008), the algorithms of the methods are embedded in software products such as Erdas Imagine, Envi (Trinh1 \& Zabloskii, 2019).

Table 4

Ratio Algorithms on Landsat 7

\begin{tabular}{|c|l|c|l|}
\hline № & Indexes & Formula & \multicolumn{1}{c|}{ References } \\
\hline 1 & NDVI & $(4-3) /(4+3)$ & ERDAS Imagine Software \\
\hline 2 & IR/R & $4 / 3$ & ERDAS Imagine Software \\
\hline 3 & Veg. index & $4 / 3$ & ERDAS Imagine Software \\
\hline 4 & Iron oxide & $3 / 1$ & ERDAS Imagine Software \\
\hline 5 & Clay minerals & $5 / 7$ & ERDAS Imagine Software \\
\hline 6 & Ferrous minerals & $5 / 4$ & ERDAS Imagine Software \\
\hline 7 & Mineral composite & $5 / 7,5 / 4,3 / 1$ & ERDAS Imagine Software \\
\hline 8 & Hydrothermal composite & $5 / 7,3 / 1,4 / 3$ & ERDAS Imagine Software \\
\hline
\end{tabular}

Among all the methods listed in Table 4, the NDVI method is widely used. For example, this method is used to search for healthy plants among infected ones using the Parrot Sequoia multispectral camera (Cerreta et al., 2018).

Below is attached a table on the Aster satellite image containing the types of algorithms for detecting minerals (Table 5). 
Table 5

Aster Satellite Imaging

\begin{tabular}{|c|c|c|c|}
\hline № & Types of minerals & Formula & References \\
\hline 1 & Ferric iron, $\mathrm{Fe} 3+$ & $2 / 1$ & Rowan \\
\hline 2 & Ferrous iron, $\mathrm{Fe} 2+$ & $5 / 3+1 / 2$ & Rowan \\
\hline 3 & Laterite & $4 / 5$ & Bierwith \\
\hline 4 & Gossan & $4 / 2$ & Volesky \\
\hline 5 & Ferrous Silicates (biot, chl, amph) & $5 / 4$ & CSIRO \\
\hline 6 & Carbonate / Chlorite / Epidote & $(7+9) / 8$ & Rowan \\
\hline 7 & Epiote / chlorite /Amphibole & $(6+9) /(7+8)$ & CSIRO \\
\hline 8 & Amphibole / MgOH & $(6+9) / 8$ & Hewson \\
\hline 9 & Amphibole & $6 / 8$ & Bierwith \\
\hline 10 & Dolomite & $(6+8) / 7$ & Rowan, USGS \\
\hline 11 & Carbonate & $13 / 14$ & Bierwith, Nimoyima, \\
\hline 12 & $\begin{array}{l}\text { Sericite / Muscovite /Illite / } \\
\text { Smectite }\end{array}$ & $(5+7) / 6$ & $\begin{array}{c}\text { Rowan (USGS) Hewson } \\
\text { (CSIRO) }\end{array}$ \\
\hline 13 & Alunite / Kaolinite /Pyrophyllite & $(4+6) / 5$ & Hewson (CSIRO) \\
\hline 14 & Phengitic & $5 / 6$ & Rowan (USGS) \\
\hline 15 & Muscovite & $7 / 6$ & Hewson \\
\hline 16 & Kaolinite & $7 / 5$ & Hewson \\
\hline 17 & Clay & $(5 \times 7) /(6 \times 6)$ & Bierwith \\
\hline 18 & Alteration & $4 / 5$ & Volesky \\
\hline 19 & Host rock & $5 / 6$ & Volesky \\
\hline 20 & Quartz Rich Rocks & $14 / 12$ & Rowan \\
\hline 21 & Silica & $(11 \times 11) / 10 / 12$ & Bierwith \\
\hline 22 & $\begin{array}{l}\text { Basic Degree Index (gnt, cpx, epi, } \\
\text { chl) }\end{array}$ & $12 / 13$ & Bierwith, CSIRO \\
\hline 23 & $\mathrm{SiO} 2$ & $13 / 12$ & Palomera \\
\hline 24 & $\mathrm{SiO} 2$ & $12 / 13$ & Nimoyima \\
\hline 25 & Kaolinite index (KLI) & {$[4 / 5][8 / 6]$} & Other \\
\hline 26 & Alunite Index & {$[7 / 5][7 / 8]$} & Other \\
\hline 27 & Calcite index & {$[6 / 8][9 / 8]$} & Other \\
\hline 28 & Quarts index & $(11 * 11) /(10 * 12)$ & Other \\
\hline 29 & Serpentinite and talc carbonate & $5 \backslash 7$ and $4 \backslash 7$ & Other \\
\hline 30 & Granitoid rocks & 214 & Other \\
\hline 31 & Gabbro- diorite & 415 & Other \\
\hline 32 & Copper mineralization & $7 / 6$ & Other \\
\hline
\end{tabular}

\section{Methodology}

The use of the ASTER satellite image makes it possible to detect more minerals for several reasons, such as the possibility of using a combination of channels, high efficiency when integrating MNF and PCA methods, but it is also necessary to take into account the spectral characteristics of the Landsat TM satellite image, which is also convenient for automated and visual decoding of 
larger natural and man-made structures (GEOMATICS, 2009 ). To solve such problems, an algorithm for multi-stage processing of a multi-zone Landsat TM image was developed (Figure 3). The algorithm consists of the main processing steps, such as the creation and selection of thematic channels, a complex image consisting of combinations of thematic channels, a functional satellite image from a combination of complex images (Shamsiev, 2016b).

\section{Figure 3}

\section{Algorithm for Creating a Complex Functional Satellite Image}

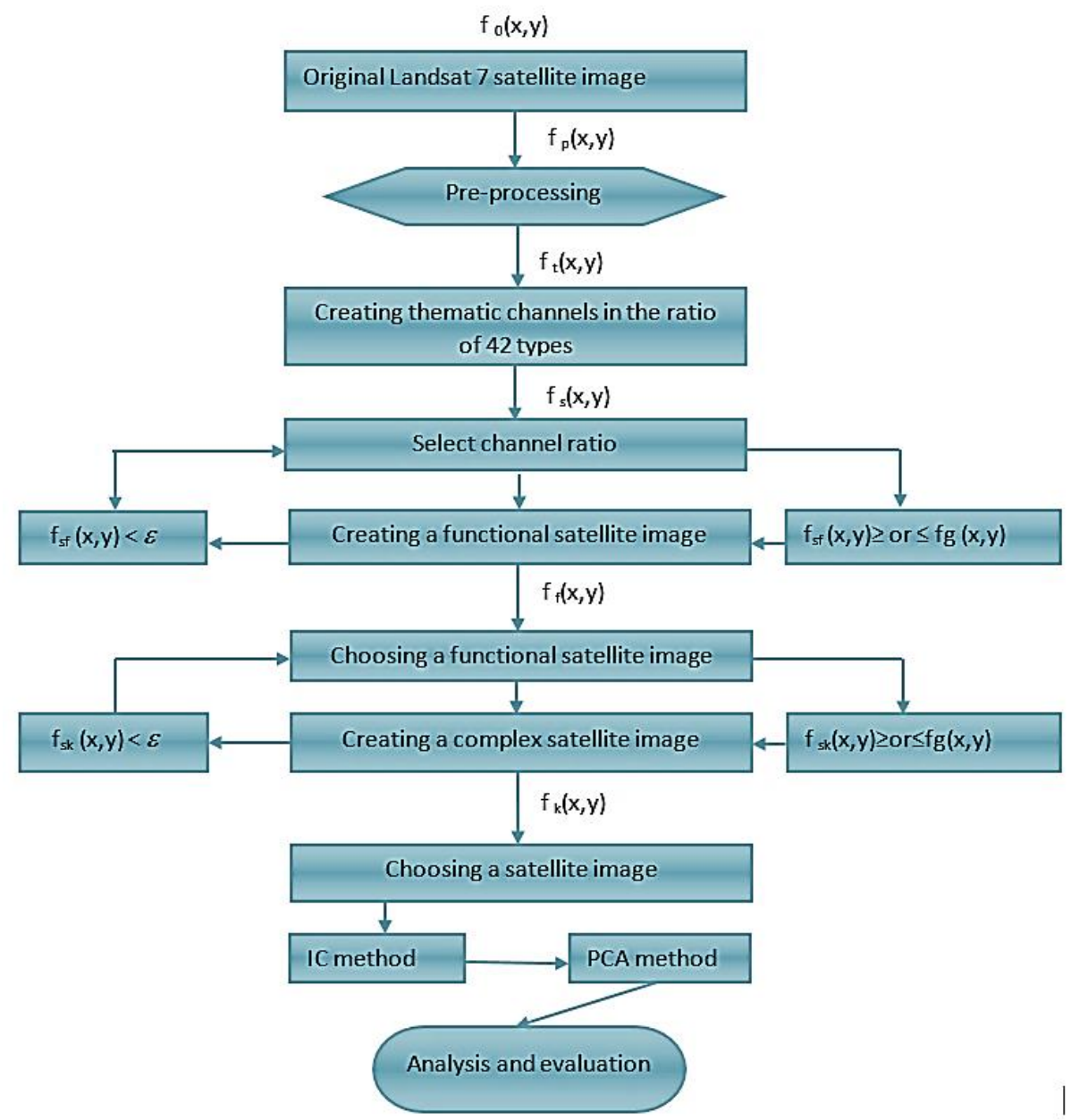

Let's take a detailed look at each stage of processing. The next process was the identification of information features for individual combinations of spectral channels. To do this, we compiled a table of RGB combinations (red- red, greengreen, blue - blue) for each sheet. On RGB, spectral channels of 7 different wave ranges were produced, and a table of 210 RGB combinations was compiled (Table 
6). One of the distinctive properties of the channel combination is that some mirror combinations of channels do not give out exactly identical informative features, for example, R1G2B3 and R3G2B1, for the rest there is a clear difference in color characteristics, but with visual decoding, these combinations can become auxiliary information for identifying individual geological structures.

Table 6

\section{$R G B$ Combinations}

\begin{tabular}{|l|l|}
\hline Geological data & $R 7 G 5 B 3, R 4 G 2 B 1, R 6 G 3 B 2, R 3 G 2 B 1, R 1 G 4 B 6, R 1 G 4 B 7, R 1 G 3 B 5$, \\
& $R 1 G 3 B 6, R 1 G 3 B 7, R 1 G 5 B 6, R 1 G 5 B 7, R 4 G 3 B 6, R 4 G 3 B 7, R 4 G 5 B 1$, \\
& $R 4 G 5 B 6, R 4 G 6 B 1, R 4 G 7 B 6, R 5 G 1 B 4, R 5 G 1 B 6, R 5 G 2 B 6, R 5 G 3 B 6$, \\
& $R 5 G 6 B 1, R 5 G 6 B 4, R 6 G 1 B 4, R 6 G 1 B 5, R 6 G 1 B 7, R 6 G 2 B 5, R 6 G 3 B 1$, \\
& $R 6 G 3 B 5, R 6 G 4 B 1, R 6 G 4 B 5, R 6 G 5 B 1, R 6 G 5 B 4, R 6 G 7 B 3, R 7 G 1 B 6, R 7 G 2 B 6$ \\
\hline Vegetation & $R 5 G 4 B 3, R 4 G 3 B 2, R 1 G 4 B 2, R 1 G 4 B 5, R 1 G 4 B 6, R 1 G 4 B 7, R 1 G 3 B 7$, \\
& $R 1 G 5 B 2, R 1 G 5 B 6, R 1 G 5 B 7, R 3 G 2 B 6, R 3 G 2 B 7, R 4 G 3 B 5, R 4 G 3 B 6$, \\
& $R 4 G 5 B 6, R 4 G 7 B 6, R 5 G 1 B 4, R 5 G 1 B 6, R 5 G 2 B 6, R 5 G 3 B 6, R 5 G 4 B 1$, \\
& $R 5 G 4 B 6, R 6 G 3 B 4, R 6 G 4 B 5, R 6 G 5 B 4, R 7 G 1 B 4, R 7 G 1 B 6, R 7 G 2 B 4$, \\
\hline Hydrological & $R 7 G 2 B 6, R 7 G 4 B 6$ \\
systems & $R 6 G 5 B 4, R 1 G 3 B 4, R 1 G 5 B 4, R 1 G 4 B 6, R 1 G 5 B 6, R 1 G 5 B 7, R 2 G 3 B 4$, \\
& $R 3 G 2 B 4, R 4 G 1 B 2, R 4 G 3 B 5, R 4 G 3 B 6, R 4 G 5 B 6, R 4 G 6 B 1, R 5 G 1 B 4$, \\
& $R 5 G 1 B 6, R 5 G 2 B 4, R 5 G 2 B 6, R 5 G 3 B 4, R 5 G 3 B 6, R 5 G 4 B 1, R 5 G 6 B 4$, \\
& $R 5 G 7 B 4, R 6 G 1 B 4, R 6 G 2 B 4, R 6 G 3 B 4, R 7 G 1 B 4$ \\
\hline
\end{tabular}

After the preliminary processing, we proceed to the creation of thematic channels. As shown in the table, the choice of combinations of thematic channels for creating a complex image is very wide. Various combinations of thematic channels (Table7).

Table 7

Combinations of Thematic Channels

\begin{tabular}{|l|l|l|l|l|l|l|l|}
\hline № & $\mathbf{1}$ & $\mathbf{2}$ & $\mathbf{3}$ & $\mathbf{4}$ & $\mathbf{5}$ & $\mathbf{6}$ & $\mathbf{7}$ \\
\hline 1 & $1 / 2$ & $2 / 1$ & $3 / 1$ & $4 / 1$ & $5 / 1$ & $6 / 1$ & $7 / 1$ \\
\hline 2 & $1 / 3$ & $2 / 3$ & $3 / 2$ & $4 / 2$ & $5 / 2$ & $6 / 2$ & $7 / 2$ \\
\hline 3 & $1 / 4$ & $2 / 4$ & $3 / 4$ & $4 / 3$ & $5 / 3$ & $6 / 3$ & $7 / 3$ \\
\hline 4 & $1 / 5$ & $2 / 5$ & $3 / 5$ & $4 / 5$ & $5 / 4$ & $6 / 4$ & $7 / 4$ \\
\hline 5 & $1 / 6$ & $2 / 6$ & $3 / 6$ & $4 / 6$ & $5 / 6$ & $6 / 5$ & $7 / 5$ \\
\hline 6 & $1 / 7$ & $2 / 7$ & $3 / 7$ & $4 / 7$ & $5 / 7$ & $6 / 7$ & $7 / 6$ \\
\hline
\end{tabular}

From the above-mentioned thematic channels, 22 types were selected based on experimental calculations, previously conducted cosmogeological works (Table 8). 
Table 8

Experimental Calculations

\begin{tabular}{|c|c|c|c|c|c|}
\hline Quantity & \multicolumn{5}{|c|}{ Additional thematic channels } \\
\hline \multirow{3}{*}{22} & $5 / 7$ & $5 / 4$ & $3 / 1$ & $4 / 3$ & $5 / 3$ \\
\cline { 2 - 6 } & $5 / 2$ & $5 / 1$ & $4 / 7$ & $3 / 7$ & $2 / 7$ \\
\cline { 2 - 6 } & $1 / 7$ & $3 / 2$ & $4 / 2$ & $1 / 2$ & $5 / 6$ \\
\cline { 2 - 6 } & $7 / 6$ & $4 / 6$ & $3 / 6$ & $2 / 6$ & $1 / 6$ \\
\cline { 2 - 6 } & $6 / 1$ & $6 / 2$ & & & \\
\hline
\end{tabular}

This calculation of the spectral channel ratios is performed using the division module of the software product ERDAS Imagine. The division algorithm of the existing module has been improved, and the channel division process takes place in one stage.

The results of each channel ratio will be included in the build operation of the thematic channels. This type of assembly algorithm exists separately in the decryption catalog as standard processing tools. That is, if you resort to the goal of saving time and quickly solving the tasks set, you can bring several types of algorithms into a complex form and avoid routine step-by-step standard treatments. After assembling the functional satellite image, visual decoding and analysis of the received images are carried out, each combination of thematic channels will be analyzed in detail for information content. To do this, various methods of comparison are used for direct and indirect signs.

The mapping is performed using software modules and ArcGIS using geological maps.

It turns out that the information content is unstable in relation to the algorithm, each collected satellite image and passed mosaicing can react to the processing of the ratio algorithms in different ways. When the channels of one image are combined, the color characteristics and channel combinations may differ significantly from the others. This factor implies the transition to another stage, the creation of a complex functional snapshot. When viewing the features of the results of the ratio algorithm for creating a functional satellite image, each functional satellite image has its own disadvantages and advantages. Weeding out the shortcomings and using the preferred combinations of thematic channels allowed us to create 5 variants of complex satellite images (Table 9). 


\section{Table 9}

Complex Satellite Images

\begin{tabular}{|c|c|c|}
\hline № & Comlex satellite image & Number of additional channels \\
\hline 1 & $5 / 75 / 44 / 3$ & 3 \\
\hline 2 & $5 / 43 / 14 / 3$ & 3 \\
\hline 3 & $6 / 16 / 25 / 75 / 43 / 14 / 3$ & 4 \\
\hline 4 & $6 / 16 / 26 / 3$ & 3 \\
\hline 5 & $5 / 67 / 64 / 63 / 62 / 61 / 6$ & 6 \\
\hline
\end{tabular}

A comprehensive satellite image is primarily the final result for further analysis and evaluation of the identified geological structures. Amplification of the brightness characteristics and boundaries of structural objects is usually performed using well-known methods.

The analysis of software tools showed their difference in mathematical approaches to solving problems, that is, processing a satellite image using one method of one program does not mean processing a satellite image using the same method in another program. This difference led to the use of the developed algorithms in a complex of well-known and frequently used GIS programs (ArcGIS 9.3, ERDAS Imagine 9.2, ENVI 4.7), depending on the information content of the results obtained. For this type of processing, an algorithm for using software tools at different stages of computational experiments to identify structural differences between objects in satellite images has been developed (Shamsiev, 2016c).

In these successive stages of satellite image processing, the above GIS programs are applied (Figure 4). The total number of steps for calculating the main component is 12 . 


\section{Figure 4}

Block Diagram of the Algorithm

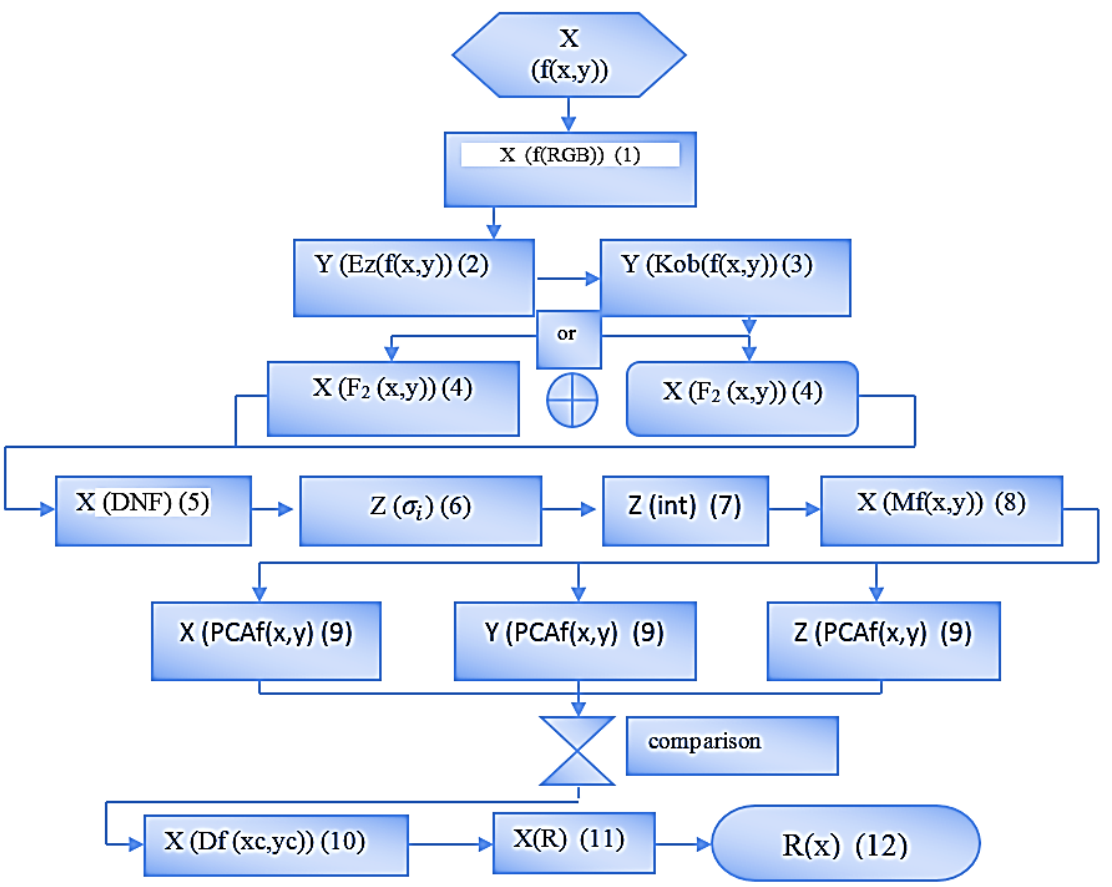

where $\mathrm{X}$ denotes the software tool Erdas Imagine, Y-ENVI, Z-ArcGIS, (1), (2) calculation steps.

Let's consider the stages of performing the structural difference algorithm, concerning the objects of man-made and natural objects.

The first stage begins with the selection of a combination of spectral channels.

The second stage is radiometric correction. The initial values of the images are given in physical units in order to adequately compare them with the data of other surveys (Egorov \& Bartalev, 2016). In the third stage, atmospheric correction is performed using a standard method developed by Pat S. Chaves, Jr. proposed in the 90 years of the last century for Landsat-5, where the pixel brightness values are converted into the values of the radiation of the solar beam received by the device. In the fourth stage, the "Landsat 7" is converted from 16 bits to 8 bits. In the fifth stage, the resolution increases due to the 8th spectral channel (15 meters). As shown in Figure 5, the converted image is compared to the original image, as seen in the 15-meter image, man-made objects are more clearly visible (Figure 5). 
Figure 5

Converted image

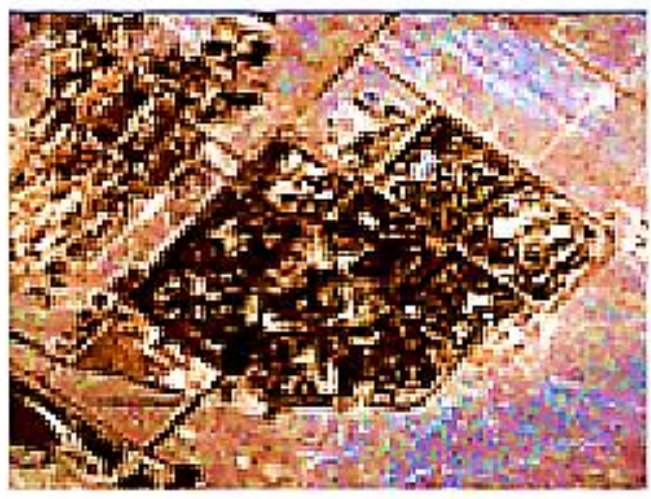

a)

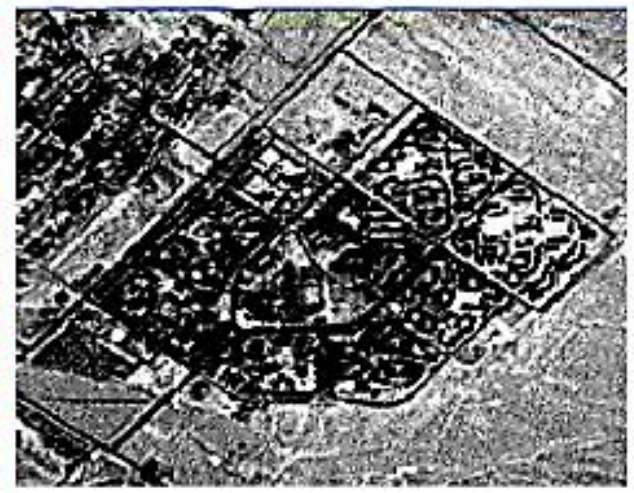

b)
a. original image
b. panchromatic

At the 6th stage, a Gaussian filter is used to blur the color characteristics of the satellite image, that is, the so-called noise suppression is carried out. However, due to the strong scattering of the blue color by the atmosphere, little is used, but radiometric and atmospheric correction is carried out for this (Zabelin \& Tulegulov, 2011). Then, at the 7th stage, the interpolation methods are applied (Getreuer, 2011). At the 8th stage, the boundaries of the objects are highlighted. The 9th stage consists of the analysis of the main components (Figure 6). 


\section{Figure 6}

Satellite Image (14 channel) Obtained by the Method of Analysis of the Main Component in the Software Erdas Imagine

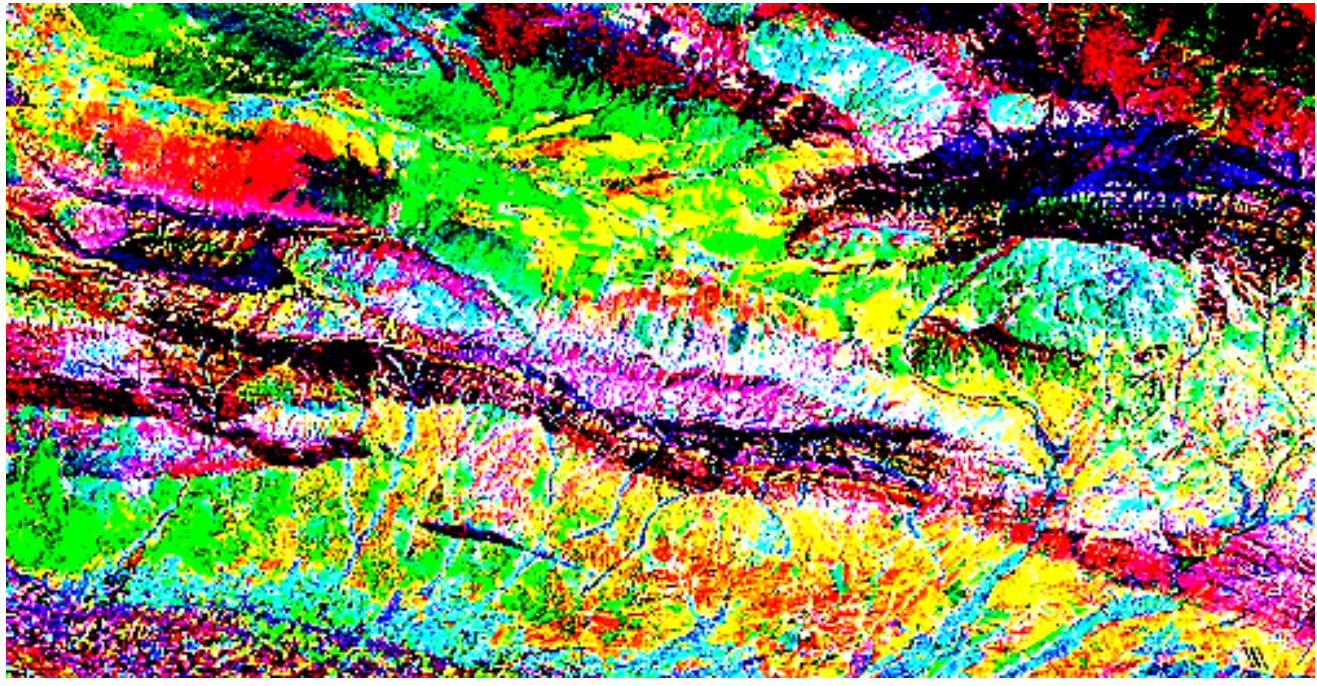

Much attention is paid to the classification, which allows us to identify elements of natural structures that are close in spectral values. The goal of most existing approaches to classifying objects in a satellite image is to create general classification models that take into account the full range of characteristics of the surrounding object data. The trained classification belongs to a group of tools for controlled information extraction. The purpose of the classification is to define the elements of the data structure as a whole. After the training classification, we will perform cluster analysis, that is, automated classification, dividing objects into $\mathrm{k}$ clusters. This procedure allows you to identify the concentration of objects in the satellite image.

The next stage of the integrated approach is a method designed for clustering, allowing you to effectively determine the features of images, such as the presence of borders and shapes of objects. This clustering method, unlike the standard one, takes into account the boundaries and integrity of objects and allows you to significantly reduce the number of cases when the block boundaries divide the object visible in the image into separate parts, in some cases scattered. The block diagram of the clusterization algorithm is shown below (Figure7). 
Figure 7

Block Diagram of the Clusterization Algorithm

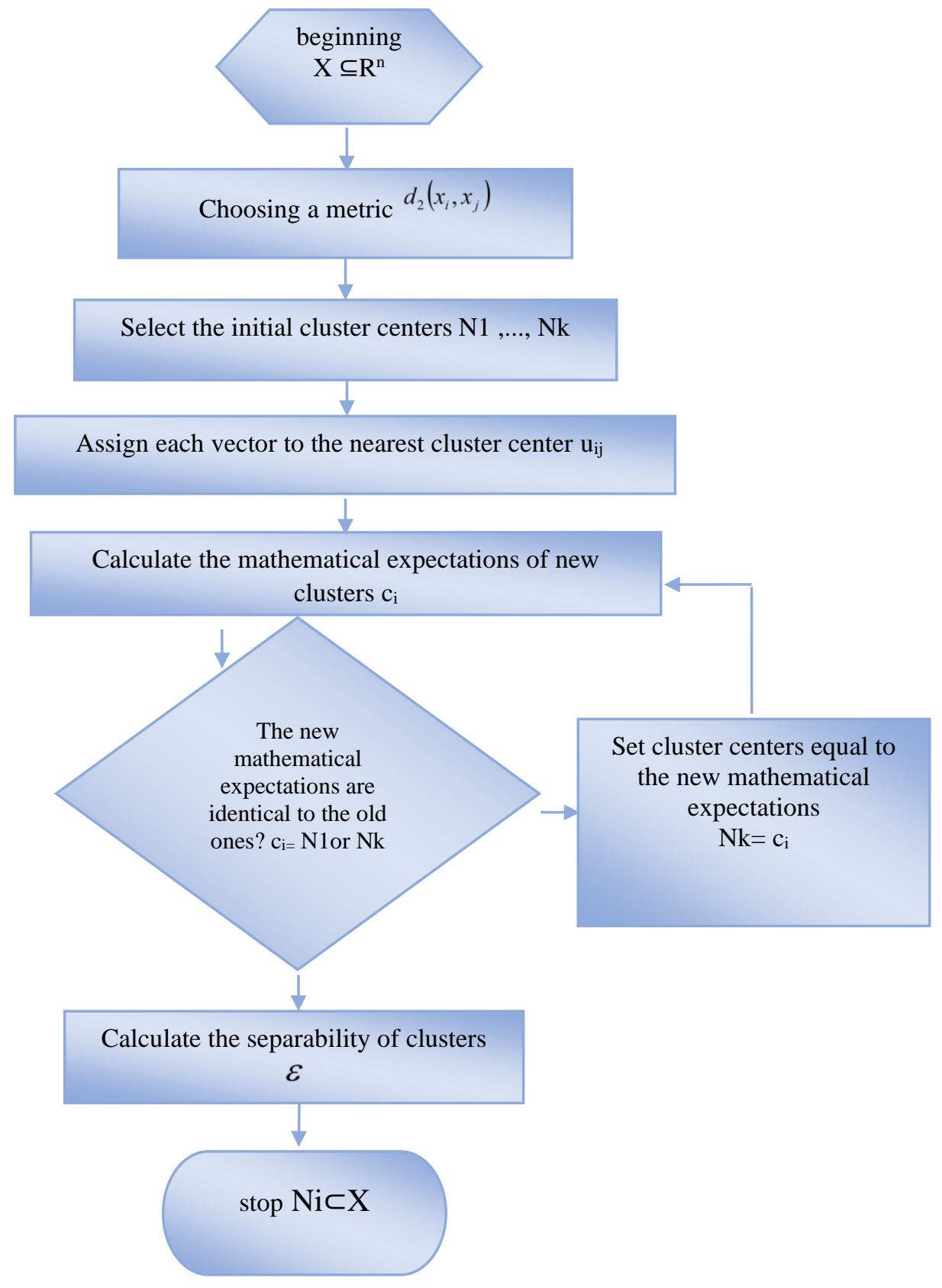

Processing the satellite image using this algorithm allowed us to identify natural (geological) objects that were hidden in previous images. The use of this approach can be applied to other satellite images of the Landsat TM type. 
The results obtained and their comparison with cartographic data on the example of the Samarkand region to assess the accuracy of segmentation are shown in Table 10.

\section{Table 10}

\section{Segmentation}

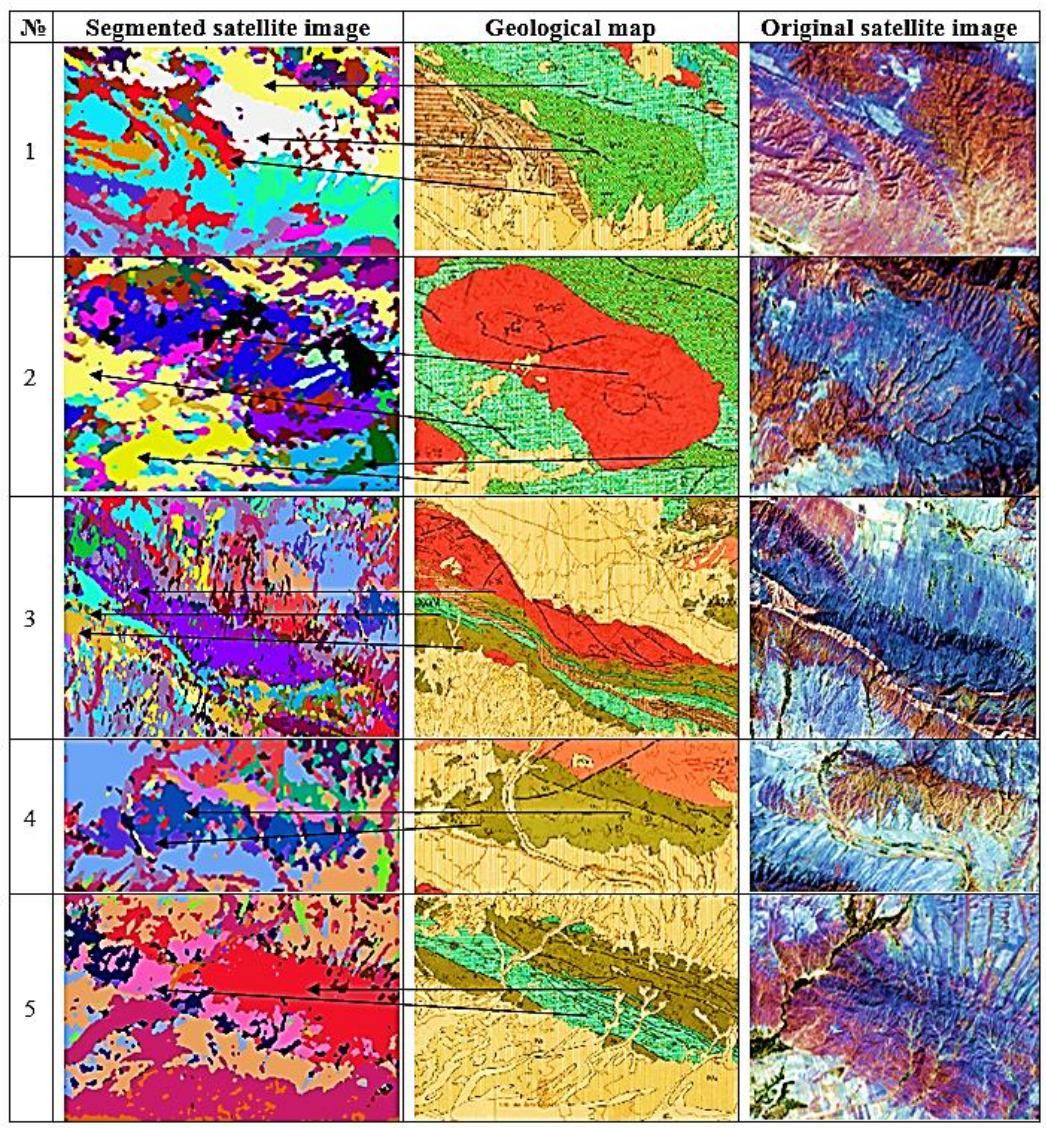

As you can see in Table 10, the image that has passed segmentation has a greater amount of information content than the original one. The accuracy of the coordinates of the areas of various natural structures for ground work remains very important, since the cartographic data is taken from ground work, it is unlikely that there is a technology for calculating the boundaries of huge areas and recognizing their structure. For the next stages, well-known algorithms are used to identify already clear boundaries of natural or man-made objects in the form of linear images, such as the algorithms Contour, Canny, Roberts, LoG, Previtt, Kirsch, and Susan. These algorithms solve problems related to the thickness of contour lines while preserving the distribution of color intensity across object classes. 


\section{Conclusions}

Processing the satellite image using this algorithm allowed us to identify geological objects that were hidden in previous images. The use of this approach can be applied to other satellite images of the Landsat TM type. The software modules used according to the above algorithms are embedded in the public software ERDAS IMAGINE, ArcGIS, ENVI.

Currently, work continues on improving and developing integrated approaches to processing satellite images with the study of the properties and capabilities of modern methods, algorithms, functions and their relationship.

The developed algorithms can also be applied in other data of survey systems. In recent years, small-format aerial photography (SFAP) has become increasingly important in many areas. This type of photography refers to a wide range of aerial photographs and camera types used to collect aerial images of the earth's surface, but it is usually used in relation to capturing images at low altitudes using small, consumer cameras as opposed to scientific sensors (Aber et al., 2018).

The developed technology for processing satellite images demonstrated the possibility of implementing the proposed methodology with the complex use of open source software. The experimental calculation of the choice of information systems for processing each stage of the satellite image is carried out.

A cycle of step-by-step processing is carried out using mathematical algorithms such as the algorithm for dividing and assembling thematic channels, complex-functional satellite images, calculating the main component using different software systems, clustering and segmentation.

As a result, images with high comparability with cartographic data were obtained on the example of the Samarkand region. 


\section{References}

Aber J. W., Babb T. A., Campbell D. E., \& Corns K. M. (2018). A comparison of the strengths and weaknesses of small-format aerial photography platforms. International Journal of Aviation, Aeronautics, and Aerospace, 5(3). https://doi.org/10.15394/ijaaa.2018.1246

Cerreta, J., Hanson, A., Martorella, J. E., \& Martorella, S. (2018). Using 3 dimension health vegetation index point clouds to determine HLB infected citrus trees. Journal of Aviation/Aerospace Education \& Research, 28(1). https://doi.org/10.15394/jaaer.2018.1776.

Dony, R. D. (2001). "Karhunen-Loève Transform". The transform and data compression handbook. Ed. K. R. Rao and P.C. Yip. Boca Raton, CRC.

Egorov, V. A., \& Bartalev, S. A. (2016). Method of radiometric correction of distortions of the reflective characteristics of the earth's surface in satellite measurement data caused by the influence of terrain. Modern Problems of Remote Sensing of the Earth from Space, 13(5), 192-201.

GEOMATICS. (2009). Review of the application of multispectral remote sensing data and their combinations in digital processing. Remote Sensing Data Processing, 56-64.

Getreuer, P. (2011). Linear methods for image interpolation. Image Processing On Line, 1, 1-22. http://dx.doi.org/10.5201/ipol.2011.g lmii

Kravtsov, S. L. (2008). On the application of remote sensing data in geology. INFORMATICS, 3, 70-80.

Lehrer, H., \& Bowen, B. D. (2003). A remote-sensing and GIS demonstration project for the Santee Sioux Indian Reservation. Retrieved from https://commons.erau.edu/ni-s3adiii-presenations/2

Shamsiev, R. Z. (2013). Features of the automated method for detecting linear structures using Landsat TM images. Materials of the Republican Scientific and Technical Conference. Tashkent State Technical University. 2013, Tashkent.

Shamsiev R. Z. (2016a). Algorithm for detecting ore fields using spectral values of the satellite image. Scientific and Technical Information and Analytical Journal, TSTU, 1(94).

Shamsiev, R. Z. (2016b). Analysis and evaluation of software modules for digital processing of satellite images. Scientific and Technical Information and Analytical Journal, TUIT, 2(38).

Shamsiev R. Z. (2016c). Recognition of structural differences in satellite images. Scientific and Technical Information and Analytical Journal, TUIT, 3(39).

Trinh1, L. H., \& Zabloskii, V. R. (2019). The method of detection of clay minerals and iron oxide based on Landsat multispectral images (as 
exemplified in the territory of Thai Nguyen Province, Vietnam). Mining Science and Technologies, 4(1). doi:10.17073/2500-0632-2019-1-65-75

Zabelin, S. A., \& Tulegulov, A. D. (2011). Methods of atmospheric correction of Landsat images. L. N. Gumilyov atyndagy EUU Khabarshysy-Bulletin of the L. N. Gumilyov ENU, 6, 147-154. 